OPEN ACCESS

Edited by:

Michele Papa

University of Campania Luigi

Vanvitelli, Italy

Reviewed by:

Chenju Yi,

Sun Yat-sen University, China Alessio Di Fonzo,

IRCCS Ca' Granda Foundation

Maggiore Policlinico Hospital, Italy

${ }^{*}$ Correspondence:

Rihua Jin

kimrh@jlu.edu.cn

${ }^{\dagger}$ These authors have contributed equally to this work

Received: 27 April 2020 Accepted: 23 February 2021

Published: 17 March 2021

Citation:

Bai Y, Su X, Piao L, Jin Z and Jin R (2021) Involvement of Astrocytes and microRNA Dysregulation in Neurodegenerative Diseases: From Pathogenesis to Therapeutic

Potential.

Front. Mol. Neurosci. 14:556215. doi: 10.3389/fnmol.2021.556215

\section{Involvement of Astrocytes and microRNA Dysregulation in Neurodegenerative Diseases: From Pathogenesis to Therapeutic Potential}

\author{
Yang Bai ${ }^{1+}$, Xing Su${ }^{2+}$, Lianhua Piao ${ }^{3}$, Zheng Jin $^{1}$ and Rihua $\mathrm{Jin}^{1 *}$ \\ ${ }^{1}$ Department of Neurosurgery, The First Hospital of Jilin University, Changchun, China, ${ }^{2}$ Department of Clinical Laboratory, \\ The Second Hospital of Jilin University, Changchun, China, ${ }^{3}$ College of Basic Medical Sciences, Jilin University, Changchun, \\ China
}

Astrocytes are the most widely distributed and abundant glial cells in the central nervous system (CNS). Neurodegenerative diseases (NDDs) are a class of diseases with a slow onset, progressive progression, and poor prognosis. Common clinical NDDs include Alzheimer's disease (AD), Parkinson's disease (PD), amyotrophic lateral sclerosis (ALS), and Huntington's disease (HD). Although these diseases have different etiologies, they are all associated with neuronal loss and pathological dysfunction. Accumulating evidence indicates that neurotransmitters, neurotrophic factors, and toxic metabolites that are produced and released by activated astrocytes affect and regulate the function of neurons at the receptor, ion channel, antigen transfer, and gene transcription levels in the pathogenesis of NDDs. MicroRNAs (miRNAs) are a group of small non-coding RNAs that play a wide range of biological roles by regulating the transcription and post-transcriptional translation of target mRNAs to induce target gene expression and silencing. Recent studies have shown that miRNAs participate in the pathogenesis of NDDs by regulating astrocyte function through different mechanisms and may be potential targets for the treatment of NDDs. Here, we review studies of the role of astrocytes in the pathogenesis of NDDs and discuss possible mechanisms of miRNAs in the regulation of astrocyte function, suggesting that miRNAs may be targeted as a novel approach for the treatment of NDDs.

Keywords: astrocytes, neurodegenerative diseases, miRNAs, biomarkers, treatment

\section{INTRODUCTION}

Neurodegenerative diseases (NDDs) refer to slowly progressive neurological diseases that are caused by neuronal degeneration and apoptosis (Heemels, 2016). Clinically, NDDs mainly include Alzheimer's disease (AD), Parkinson's disease (PD), Huntington's disease (HD), and amyotrophic lateral sclerosis (ALS). Neurodegenerative diseases mainly manifest as motor and cognitive dysfunction (Giovagnoli et al., 2018; Ruppert et al., 2020). Histopathological studies of these diseases have shown that neurons slowly and gradually 
become apoptotic, exhibit abnormal protein aggregation, and form inclusion bodies, suggesting that they may have similar disease progression mechanisms (Lau et al., 2020).

Astrocytes are widely distributed glial cells in the central nervous system (CNS), the abundance of which is 10- to 50-times higher than neurons (Ridet et al., 1997). Astrocytes confer the basic skeleton of the CNS and participate in its functional activity (Khakh and Sofroniew, 2015). The main functions of astrocytes include: (i) the synthesis and secretion of various cytokines, playing an important role in the survival, development, and differentiation of neurons (Sofroniew, 2014); (ii) support, isolation, and insulation (Liddelow and Barres, 2017); (iii) the regulation of neuronal metabolism and stabilization of the microenvironment, transporting neuroactive amino acids, participating in glucose metabolism, regulating intracellular calcium levels, and buffering potassium ions (Sofroniew and Vinters, 2010); (iv) the synthesis and secretion of neurotrophic factors, chemokines, and cytokines that participate in immune responses to neurological diseases (Brambilla, 2019); (v) the promotion of nerve regeneration and repair (Anderson et al., 2016); (vi) participation in the migration of axons and neuroblasts (Seyedhassantehrani et al., 2016); (vii) antioxidant damage; and (viii) interactions with neurons in information exchange and neurotransmitter transfer (Bachoo et al., 2004). Increases in calcium concentrations in astrocytes enhance excitability and play an important role in synapses, the number and efficiency of synapses, the formation of neural nuclei, and the development of NDDs (Lind et al., 2018). Astrocytes also participate in formation of the blood-brain barrier (BBB). The $\mathrm{BBB}$ is composed of endothelial cells, a basement membrane, astrocyte foot processes, microglia, and an extracellular matrix. The dysfunction of astrocytes, the $\mathrm{BBB}$, and neurons plays an important role in NDDs.

Numerous studies in recent years have shown that microRNAs (miRNAs) are abnormally expressed in neurons during the pathogenesis of NDDs (Goodall et al., 2013). miRNAs are involved in the pathogenesis of NDDs by directly or indirectly regulating the function of astrocytes. miRNAs have a relatively small molecular weight. They can readily pass the $\mathrm{BBB}$ and exhibit stable expression in peripheral blood (Leidinger et al., 2013), which can be isolated and examined by standard laboratory techniques. miRNAs have been widely studied concerning the diagnosis and pathogenesis of NDDs. Here, we review recent studies of the role of astrocytes in the pathogenesis of NDDs and discuss possible mechanisms of miRNAs in regulating astrocyte function, suggesting that miRNAs can be targeted as a novel approach for the treatment of NDDs.

\section{PATHOLOGICAL FUNCTIONS OF ASTROCYTES IN NEURODEGENERATIVE DISEASES}

The activation of astrocytes is a main pathological feature of NDDs and an adaptive defense response that provides essential metabolic support for neurons. The formation of free radicals, inflammation, elevations of the excitatory neurotransmitter glutamate, and neuronal degeneration that are caused by the dysfunction of astrocyte activation are closely related to the development of NDDs (Liddelow et al., 2017; Rivetti Di Val Cervo et al., 2017; Neal and Richardson, 2018; Yamanaka and Komine, 2018). Astrocytes are diverse types of glial cells with complex and diverse structures and functions. Accumulating evidence indicates that astrocytes present differences in morphological structure, molecular expression, basic function, and stress response. The activation of astrocytes in NDDs is a complex and multifaceted process. During this process, astrocyte-related gene and protein expression and the morphological structure and physiological function of astrocytes undergo progressive changes. The absence of the original function of astrocytes or an increase in the toxic function of astrocytes can cause nerve excitotoxicity, oxidative stress, and inflammatory response in NDD development (Acosta et al., 2017; Neal et al., 2018; Kaur et al., 2019). Also, recent studies have shown that abnormal or degenerative astrocytes can severely disrupt the transmission of information between astrocytes and neurons, resulting in neuronal dysfunction and NDDs (Turnquist et al., 2016; Gómez-Gonzalo et al., 2017; Bussian et al., 2018; Di Domenico et al., 2019). Therefore, astrocytes can play a crucial role in the pathogenesis of NDDs (Table 1).

\section{ASTROCYTES AND ALZHEIMER'S DISEASE}

The inflammatory response in the brain in $\mathrm{AD}$ patients involves the activation of microglia and astrocytes, morphological changes in microglia, and increases in the number, volume, and activity of astrocytes (Meraz-Ríos et al., 2013). Activated astrocytes can also cause neuropathological changes through the expression of a large number of inflammatory factors. The expression of cytokines [e.g., interleukin-1 $\beta$ (IL-1 $\beta$ ), IL-6, tumor necrosis factor- $\beta$ (TNF- $\alpha$ ), and transforming growth factor- $\beta$ (TGF- $\beta$ )] is upregulated before amyloid- $\beta(\mathrm{A} \beta)$ aggregation and tau protein hyperphosphorylation, indicating that neuroinflammation is involved in early stages of AD (Schuitemaker et al., 2009). Inflammatory factors can also activate astrocytes to produce A $\beta$. For example, interferon- $\gamma$ (IFN- $\gamma$ ), together with TNF- $\alpha$ and IL- $1 \beta$, can stimulate astrocytes to produce a large number of $A \beta_{1-40}$ and $A \beta_{1-42}$ proteins (Blasko et al., 2000). Amyloid $\beta$, in turn, activates astrocytes to release more cytokines. For example, $\mathrm{A} \beta$ has been shown to increase TNF- $\alpha$ levels, which is considered a factor that is involved in $\mathrm{AD}$-related cognitive impairment (Veeraraghavalu et al., 2014; Yang et al., 2016). In the brain in $\mathrm{AD}$ patients, reactive astrocytes were reported to overexpress $\beta$-secretase 1 (BACE-1) mRNA and protein levels and promote the production of $A \beta$ (Rossner et al., 2005). In $\mathrm{AD}$, activated astrocytes can form halos that surround neuritic plaques. The formation of $\mathrm{A} \beta$ is closely related to activated astrocytes (Yang, 2019). Additionally, astrocytes participate in $A \beta$ uptake and clearance from brain parenchyma to the perivascular space through the $\mathrm{BBB}$. Astrocyte dysfunction leads to a decrease in $A \beta$ uptake and clearance (Rolyan et al., 2011). In vitro, $\mathrm{A} \beta$ can form a complex with apolipoprotein $\mathrm{E}$ or serum amyloid P-complement C1q (SAP-C1q) and upregulate the 
TABLE 1 | Summary of astrocyte dysfunction in neurodegenerative disease.

\begin{tabular}{|c|c|c|}
\hline Diseases & Signaling molecules/pathways/functions & References \\
\hline Alzheimer's disease & $\begin{array}{l}\text { Inflammatory factors can induce astrocyte to produce } A \beta \\
\text { Activated astrocyte promote } A \beta \text { production and inhibit } A \beta \text { degradation } \\
\text { Pathological accumulation of tau protein } \\
\text { Release of inflammatory cytokines to accelerate the formation of neurofibrillary } \\
\text { tangles }\end{array}$ & $\begin{array}{l}\text { Blasko et al. (2000) } \\
\text { Yang et al. (2016) } \\
\text { Yang (2019) } \\
\text { Birch et al. (2014) }\end{array}$ \\
\hline Parkinson's disease & $\begin{array}{l}\text { Release of inflammatory factors (TNF- } \alpha, \mathrm{IL}-6, \mathrm{NO}, \mathrm{IL}-1 \beta \text { ) } \\
\text { Astrocytes participate in oxidative stress and excitotoxicity of Parkinson's } \\
\text { disease } \\
\text { Express protein }(\mathrm{S} 100 \beta) \text { participates in the pathogenesis of Parkinson's disease }\end{array}$ & $\begin{array}{l}\text { Lee et al. (2016) } \\
\text { Morale et al. (2006) } \\
\text { Muramatsu et al. (2003) }\end{array}$ \\
\hline Huntington's disease & $\begin{array}{l}\text { Decrease Kir } 4.1 \mathrm{~K}^{+} \text {channel functional expressio } \\
\text { Impair } \mathrm{Ca}^{2+} \text { and glutamate signals } \\
\text { Alter glutamate signal and induce neuronal excitotoxicity }\end{array}$ & $\begin{array}{l}\text { Tong et al. (2014) } \\
\text { Jiang et al. (2016) } \\
\text { Bradford et al. (2009) }\end{array}$ \\
\hline Amyotrophic lateral sclerosis & $\begin{array}{l}\text { Glutamate transport dysfunction } \\
\text { Inhibitory effect of GluR2 on calcium permeation } \\
\text { Lead to mitochondrial dysfunction } \\
\text { Inflammatory factors activate caspase-3 apoptosis } \\
\text { Toxic effect of SOD1 on motor neuron } \\
\text { Oxidative stress leads to nutritional factors deficiency and SOD1 mutation }\end{array}$ & $\begin{array}{l}\text { Jordan et al. (2018) } \\
\text { Vermeiren et al. (2006) } \\
\text { Kosuge et al. (2018) } \\
\text { Kalmar et al. (2014) } \\
\text { Krishnan et al. (2008) } \\
\text { Gong et al. (2000) }\end{array}$ \\
\hline
\end{tabular}

expression of neprilysin (NEP) and scavenger receptor B family member 1 (SCARB1) in normal astrocytes, thereby inducing the further uptake of $A \beta$ through SCARB1 and degradation of $\mathrm{A} \beta$ by NEP. However, astrocytes from $\mathrm{AD}$ patients did not exhibit increases in NEP or SCARB1 gene expression in response to $\mathrm{A} \beta$-apolipoprotein $\mathrm{E}$ or $\mathrm{A} \beta$-SAP-C1q complexes. These results indicated that astrocyte function is altered in $\mathrm{AD}$ (Mulder et al., 2012). Moreover, astrocytes can be activated in the $\mathrm{AD}$ brain to promote an inflammatory cascade, and neuroinflammation, in turn, promotes tau lesions and causes the pathological accumulation of tau protein (Birch et al., 2014). In conclusion, $\mathrm{A} \beta$ and many pro-inflammatory cytokines can activate astrocytes. Reactive astrocytes can release nitric oxide (NO), IL-1, IL-6, and other proinflammatory cytokines, thereby accelerating the formation of neurofibrillary tangles (NFTs; Allaman et al., 2011).

\section{ASTROCYTES AND PARKINSON'S DISEASE}

Parkinson's disease is a kind of NDD that is characterized by the progressive loss of dopaminergic neurons in the substantia nigra of the midbrain and the formation of Lewy bodies (Zhang et al., 2017). Many previous studies explored the etiology and pathogenesis of PD from the perspective of dopaminergic neurons, but researchers have begun to realize that other important and often neglected phenomena contribute to pathological changes in the brain in PD, including the proliferation and activation of glial cells (Cacace et al., 2017). In patients with PD and animal models of PD, the substantial loss of dopaminergic neurons occurs, in addition to moderate astrocyte activation in the dense part of the substantia nigra (Kuter et al., 2018). Astrocyte activation can produce TNF- $\alpha$, IL-1 $\beta$, NO, prostaglandin-E2 (PGE-2), and other inflammatory factors. These proinflammatory factors can initiate the activation of signal transduction pathways in dopaminergic neurons in different ways, eventually leading to dopaminergic neuron loss (Lee et al., 2016). TNF- $\alpha$ binds to specific TNF- $\alpha$ receptors on dopaminergic neurons and activates the proapoptotic pathway. Studies have shown that TNF- $\alpha$ receptor activation can cause dopaminergic neurons to degenerate through activation of the intracellular $\mathrm{C}_{2}$ ceramide pathway (Hunot et al., 1997; Qin et al., 2007). The IL$1 \beta$ expression is extremely low in the normal CNS, and its expression is significantly upregulated in many inflammatory and degenerative diseases. IL-1 $\beta$ can influence the function of astrocytes, interfere with signal transmission between neurons and glial cells, and promote the pathogenesis of PD (Saghazadeh et al., 2016). Lipopolysaccharide and inflammatory factors can activate astrocytes to express inducible nitric oxide synthase (iNOS) and promote NO release (Ko et al., 2018). When astrocytes are activated by a combination of cytokines, including TNF- $\alpha$, IL- 1 , and TNF- $\gamma$, the stable astrocyte becomes highly vulnerable to apoptosis and may cause neuronal damage or cell death by releasing free radicals and glutamate (Choi et al., 1999). Astrocytes are the main detoxification site of 1-methyl-4-phenyl1,2,3,6-tetrahydropyridine (MPTP), which is metabolized to 1methyl-4-phenylpyridinium $\left(\mathrm{MPP}^{+}\right)$by monoamine oxidase $\mathrm{B}$. Once entered in dopaminergic neurons in the substantia nigra, $\mathrm{MPP}^{+}$inhibits mitochondrial complex 1 and leads to oxidative stress, the loss of adenosine triphosphate, protein nitration, and the apoptosis of dopaminergic neuron (Morale et al., 2006). $\mathrm{S} 100 \beta$ is a $\mathrm{Ca}^{2+}$-binding protein that is highly expressed in injured brain tissue. Muramatsu et al. examined the expression of $S 100 \beta$ in the striatum, substantia nigra neurons, and glial cells in mice that were subjected to MPTP-induced dopaminergic neuron injury and observed $S 100 \beta$-positive staining only in $\mathrm{GFAP}^{+}$astrocytes, indicating that astrocytes are activated in MPTP-induced dopaminergic neuron injury and may contribute to the pathogenesis of PD (Muramatsu et al., 2003). In summary, 
activated astrocytes may play different roles in the pathogenesis of $\mathrm{PD}$, which requires further study to identify their role in NDDs.

\section{ASTROCYTES AND HUNTINGTON'S DISEASE}

Huntington's disease is a progressive NDD that can lead to motor, cognitive, and mental disorders. Cytosine-adenineguanine (CAG) repeat expansions in the HTT gene lead to the formation of mutant huntingtin (mHTT; Hsiao et al., 2013). The nuclear aggregation of mHTT protein is the main cause of degeneration, inflammation, apoptosis, and neuronal loss in the cortex and striatum (Zhang et al., 2018). Astrocytes are more efficient than neurons at clearing mHTT aggregates, so astrocytes are more resistant to mHTT aggregation (Zhao et al., 2016). However, mHTT aggregation in astrocytes can alter glutamate signaling and cause neuronal excitotoxicity (Shin et al., 2005). Medium spiny neuron (MSN) dysfunction in the striatum is a characteristic change in HD. Tong et al. (2014) found that alterations of striatal MSN excitability in HD may be caused by disturbances of astrocyte-mediated $\mathrm{K}^{+}$homeostasis. In a mouse model of $\mathrm{HD}$, the frequency, duration, and amplitude of spontaneous $\mathrm{Ca}^{2+}$ signals were significantly reduced. The dysfunction of $\mathrm{Ca}^{2+}$ and glutamate signaling could be largely rescued by the astrocyte-specific restoration of Kir4.1, suggesting the important contribution of homeostatic $\mathrm{K}^{+}$mechanisms that are known to be lower in a mouse model of HD (Jiang et al., 2016). These dysfunctions lead to a reactive state of astrocytes and suggest that neurotoxicity that causes inflammation might be a secondary effect of HD. In the inflammatory state, microglia activate astrocytes to release TNF- $\beta$ and IL- $\beta$, decreasing synaptic maintenance and phagocytic activity and increasing the degeneration of neurons and oligodendrocytes (Bradford et al., 2009; Liddelow et al., 2017).

\section{ASTROCYTES AND AMYOTROPHIC LATERAL SCLEROSIS}

Amyotrophic lateral sclerosis is a chronic progressive NDD that selectively invades anterior horn cells in the spinal cord, motor neurons in the brainstem, and motor cortex (Owens, 2017). Various pathogenic factors have been proved to be involved in the pathogenesis of ALS, including glutamate excitotoxicity, copper/zinc superoxide dismutase (SOD1) gene mutations, mitochondrial dysfunction, oxidative stress, glial cell dysfunction, cytoskeleton disorders, abnormal protein folding and aggregation, nutritional factor deficiencies, and inflammation (Kiernan et al., 2011; Lyon et al., 2019).

In addition to the aforementioned mechanisms involved in the pathogenesis of ALS, recent studies have also focused on the role of astrocytes. In ALS, motor neuron protein aggregation is a hallmark of the disease. Tripathi et al. showed that reactive astrocytes increased axonal and cytoplasmic protein inclusions by releasing transforming growth factor $\beta 1$, which disrupted motor neuron autophagy through the mammalian/mechanistic target of rapamycin (mTOR) pathway (Tripathi et al., 2017).
Glutamate transport dysfunction in astrocytes is the main cause of higher extracellular glutamate levels. Increases in glutamate levels were found in cerebrospinal fluid in ALS patients. The inhibition of glutamate uptake can induce the selective degeneration of motor neurons. Glutamate transporter levels in astrocytes were downregulated in lesions of the spinal cord and motor cortex. Rothstein et al. (1995) developed Cterminal, antioligopeptide antibodies that were specific for each glutamate transporter. Excitatory amino acid transporters were selective for neurons, while glutamate transporter 1 was selective for astrocytes. They showed that the expression of glutamate transporter 1 with antisense oligonucleotides caused a dramatic elevation of extracellular glutamate and neuronal injury in specific regions of the motor cortex and spinal cord, suggesting that this change was associated with motor neuron injury (Rothstein et al., 1995; Heath and Shaw, 2002; Jordan et al., 2018). Astrocytes regulate the expression of glutamate receptor 2 (GluR2) subunits and the susceptibility of motor neurons to excitotoxicity.

Amyotrophic lateral sclerosis is associated with the expression of SOD1 mutations in astrocytes and inhibition of the ability of GluR2 to regulate $\mathrm{Ca}^{2+}$ ion penetration, thus making motor neurons more sensitive to excitotoxicity and suggesting that astrocytes affect motor neuron function (Vermeiren et al., 2006; Van Damme et al., 2007). Reactive astrocytes can damage mitochondria in co-cultured neurons (Barbeito et al., 2004). Studies have reported intracellular mitochondrial dysfunction in the pathogenesis of ALS and alterations of calcium homeostasis. A reduction of $\mathrm{Ca}^{2+}$ ions can affect neuronal transmission (Kawamata and Manfredi, 2010). Neuroinflammation plays an important role in the pathogenesis of ALS.

In recent years, inflammation in the spinal cord has received widespread attention as important pathogenesis of ALS. PGE2 , a key pro-inflammatory mediator, is elevated in serum and CSF of patients with sporadic ALS and G93A mice (Izecka, 2003; Miyagishi et al., 2017). Also, the expression of cyclooxygenase-2 (COX-2), the key enzyme for the arachidonic acid synthesis of prostaglandins, is increased in the spinal cord of ALS patients and model mice (Yasojima et al., 2001; Kosuge et al., 2018). Such cytokines as TNF- $\alpha$ and Fas L are secreted, which then activate caspase- 8 and regulate nuclear factor- $\kappa \mathrm{B}(\mathrm{NF}-\kappa \mathrm{B})$, inflammatory cytokines, chemokines, and oxygen free radicals to cause an inflammatory response in glial cells, activate the classic caspase- 3 apoptotic pathway, and affect neuronal function (Kalmar et al., 2014).

Astrocytes that express SOD1 mutations have a significant toxic effect on neurons (Krishnan et al., 2008). In transgenic mouse models of ALS, SOD1 mutations promoted cell death, and ALS neurons that expressed a SOD1 mutation were vulnerable to damage. Reductions of SOD1 expression in neurons delayed the occurrence of ALS and prolonged the life of transgenic mice (Gong et al., 2000). The pathogenesis of ALS is not the result of a single factor but rather a variety of cellular interactions. The regulation of astrocyte function, improvements in the regeneration environment of motor neurons, and promotion of the survival and regeneration of motor neurons are new research avenues that are being studied for the treatment of ALS. 


\section{INVOLVEMENT OF miRNAs IN ASTROCYTE DYSFUNCTION IN NEURODEGENERATIVE DISEASES}

microRNAs (miRNAs) are a class of endogenous non-coding single-stranded, $\sim 22$-nucleotide RNA molecules, which regulate gene expression post-transcriptionally by base-pairing with their target mRNAs (Stenvang and Kauppinen, 2008). They play an important role in cell fate determination, cell differentiation, organ development, and physiology and are also involved in various pathologies in humans (Almeida et al., 2011; Desvignes et al., 2015). miRNAs regulate target gene mRNA mainly by cutting off the target gene's RNA molecule, thereby inhibiting target gene translation and inhibiting recombination (Han et al., 2019). By binding to the RNA-induced silencing complex, the nucleotide sequence of miRNA allows targeted base pairing with the $3^{\prime}$-untranslated region of complementary mRNA. miRNA sequence-specific mRNA silencing can be achieved through two mechanisms: (i) if the miRNA-mRNA sequence is sufficiently complementary, then transcriptional cleavage will occur; and (ii) if there is a lack of complementarity but there are still some remaining complementary miRNA sites on the mRNA, then translation suppression can be achieved (Zeng et al., 2003; Bruen et al., 2019). Emerging studies suggest that many miRNAs are expressed in astrocytes, and some of them have been shown to participate in astrocyte differentiation, activation, and specification of the inflammatory response (Neal and Richardson, 2018). Neo et al. found that miR-124 increased astrocyte differentiation by directly downregulating the expression of histone-lysine $\mathrm{N}$-methyltransferase (Ezh2; Neo et al., 2014). Meares et al. (2018) reported that miR-31 promoted astrocyte development and specification by reducing the levels of Lin28, a stem cell factor that is implicated in neural precursor cell renewal. Van Scheppingen et al. (2018) reported that the miR-146a and miR-147b were differentially expressed in temporal lobe epilepsy patients with hippocampal sclerosis, and were related to increased expression of genes associated with the inflammatory response. Overexpression of miR-146a and miR-147b could reduce the expression of the pro-inflammatory mediators IL-6 and COX-2 in astrocytes and decrease the proliferation of astrocytes (Van Scheppingen et al., 2018), suggesting that these two miRNAs may be potential therapeutic targets for the treatment of neurological disorders that are associated with inflammation. To present, many studies have suggested that miRNAs are also involved in astrocyte dysfunction in NDDs (Figure 1, Table 2).

\section{INVOLVEMENT OF MIRNAS IN ASTROCYTE DYSFUNCTION IN AD}

Extracellular $\mathrm{A} \beta$ plaques and intracellular Tau protein aggregates are pathological features of $\mathrm{AD}$, accompanied by the loss of synapses, the death of neurons, and a chronic inflammatory response in astrocytes (Zhu and Wang, 2015; Tobore, 2019). miR-146a is located on chromosome 5 of the human genome and is widely expressed in the immune system. It is usually expressed at a low level in immune precursor cells, but its expression is upregulated as immune cells mature and activate (Starczynowski et al., 2011). miR-146a was reported to downregulate interleukin-1 receptor-associated kinase-1 (IRAK-1) in endotoxin- and cytokine-challenged human monocytes (Taganov et al., 2006) and specifically associated with the upregulation of inflammatory signaling in prion-induced neurodegeneration and temporal lobe epilepsy (Cui et al., 2010). Cui et al. (2010) found miR-146a was upregulated in human astrocytes that were exposed to A $\beta$. miR-146a-mediated down-regulation of IRAK-1 coupled to an NF- $\mathrm{kB}$-induced up-regulation of IRAK-2 expression drove an extensively sustained inflammatory response. The interactive signaling of NF- $\kappa B$ and miR-146a further illustrated the interplay between inducible transcription factors and pro-inflammatory miRNAs that regulate brain IRAK expression. Therefore, the combined use of NF- $\mathrm{KB}$ inhibitors with miR-146a or antisense miR-146a may be a bi-pronged treatment strategy directed against IRAK-2 driven pathogenic signals (Cui et al., 2010).

Glutamate release, reuptake, and recycling are tightly regulated by neurons and astrocytes at tripartite synapses. Glutamate overload can trigger neuronal and synaptic loss, which potentially contributes to the pathogenesis of $\mathrm{AD}$ (Marttinen et al., 2018). Glial glutamate transporter 1 (GLT-1) contributes to the clearance and regulation of glutamate at synaptic clefts. An increase in miR-181a downregulated some synaptic proteins that are involved in plasticity in a 3xTg-AD mouse model and had a negative regulatory relationship with GLT-1, suggesting that miR-181a is a key mediator of the plasticity of glutamatergic synapses by controlling the expression of synaptic proteins, including GLT-1, in astrocytes (Zumkehr et al., 2015, 2018).

miR-155 has a wide range of functions. It is involved in many biological processes, such as the development and differentiation of hematopoietic cells and immune cells. It also participates in inflammatory reactions, the immune response, muscle development, and adipose differentiation. Higher levels of miR-155 in astrocytes were shown to induce the prolongedexpression of proinflammatory cytokines by targeting SOCS1, a negative regulator of the inflammatory gene response, in $\mathrm{A} \beta$ treated astrocytes (Guedes et al., 2014). These data showed that the pathogenesis of $\mathrm{AD}$ is characterized by distinct neuroinflammatory events that involve the dysregulation of miRNA expression in astrocytes.

\section{INVOLVEMENT OF miRNAS IN ASTROCYTE DYSFUNCTION IN PD}

Parkinson's disease is related to various pathological factors, including $\alpha$-synuclein toxicity and other mechanisms. Cressatti et al. found the serum concentrations of miR-153 and miR-223 progressively decreased in the wild-type (WT) and GFAP.HMOX1 mice. Also, circulating levels of both miRNAs were lower in the transgenic mice compared to WT controls, while $\alpha$-synuclein protein concentrations were elevated in GFAP.HMOX1 mice, relative to WT 


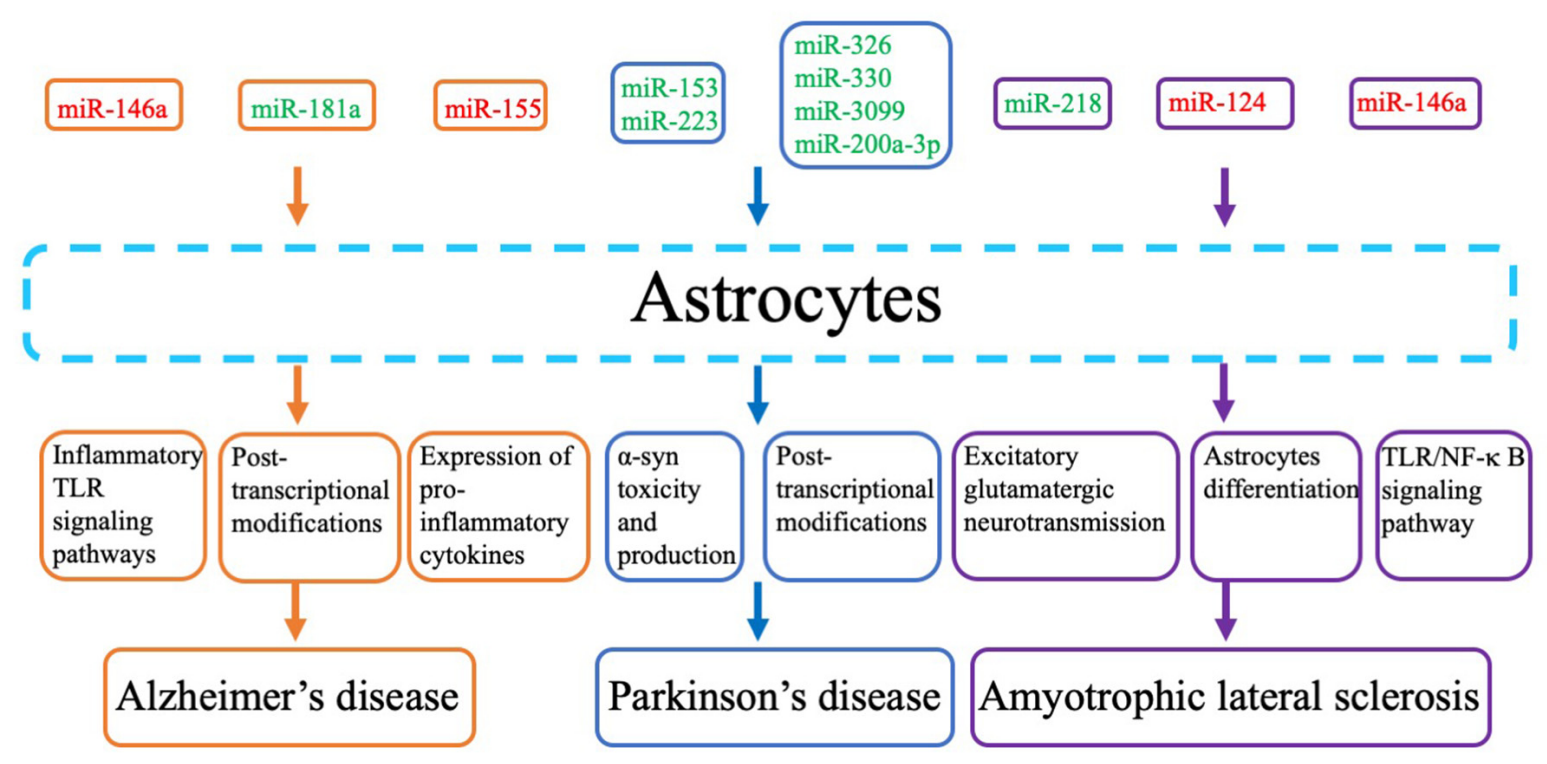

FIGURE 1 | Pathogenic mechanisms and pathways and related microRNAs (miRNAs) that are considered key molecular players in the contribution of astrocytes tossssss neurodegenerative diseases. Red miRs indicate upregulated miRNAs, and green miRs indicate downregulated miRs.

TABLE 2 | Important miRNAs and their targets that are involved in regulating astrocyte during neurodegenerative diseases (NDDs).

\begin{tabular}{|c|c|c|c|c|}
\hline NDDs & MicroRNA implicated & Targets (mRNA) & Involved in (signaling) pathways & References \\
\hline \multicolumn{5}{|l|}{$A D$} \\
\hline & miR-146a & IRAK-1, IRAK-2 & Inflammatory TLR signaling pathways & Cui et al. (2010) \\
\hline & miR-181a & GLT-1 & Post-transcriptional modifications & Zumkehr et al. (2018) \\
\hline \multicolumn{5}{|c|}{ r } \\
\hline & miR-153, miR-223 & $\mathrm{HO}-1$ & $\alpha$-syn toxicity and production & Cressatti et al. (2019) \\
\hline & miR-326, miR-330 and miR-3099 & PINK1 & post-transcriptional modifications & Choi et al. (2016) \\
\hline & miR-218 & EAAT2 & Excitatory glutamatergic neurotransmission & Ferraiuolo and Shaw (2018) and Ridler (2018) \\
\hline & miR-124 & Sox2, Sox9 & Astrocytes differentiation & Zhou et al. (2018) \\
\hline & $m i R-146 a$ & IRAK1, TRAF6 & TLR/NF-kB signaling pathway & Gomes et al. (2019) \\
\hline
\end{tabular}

AD: Alzheimer's disease; ALS: amyotrophic lateral sclerosis; NDDs: neurodegenerative diseases; PD: Parkinson's disease.

values, both of these miRNAs negatively regulated $\alpha$ synuclein in the basal ganglia in GFAP.HMOX1 mice. Moreover, the overexpression of heme oxygenase-1 (HO-1) in stressed astrocytes was observed in the substantia nigra in idiopathic PD, which promoted $\alpha$-synuclein toxicity and production by downregulating miR-153 or miR-223 in the CNS (Cressatti et al., 2019).

miR-326, miR-330, and miR-3099 were reported to be associated with astroglioma. The expression of these three miRNAs increased during brain development and neural stem cell (NSC) differentiation and was significantly lower in the PTEN-induced putative kinase 1 (PINK1)knockout mouse brains. Choi et al. (2016) found that three astrocyte-related miRNAs (miR-326, miR-330, and miR-3099) increased NSC differentiation into astrocytes and were significantly downregulated in the absence of the PD gene phosphatidylinositol 3,4,5-trisphosphate 3- phosphatase and dual-specificity protein phosphatase PINK1 (Choi et al., 2016).

$\mathrm{MPP}^{+}$is a well-known neurotoxin that is used to induce cell death in vitro in models of PD. miR-200a-3p was reported to be downregulated in $\mathrm{MPP}^{+}$-stimulated astrocytes. Mitogenactivated kinase- kinase 4 (MKK4) is involved in the mechanism of PD-related cell death (Saporito et al., 2000). Ogura et al. demonstrated that MKK4 inhibition could rescue cells from cell death, indicating that MKK4 played an important role in $\mathrm{MPP}^{+}$-induced cell death and possibly in $\mathrm{PD}$ pathogenesis (Ogura et al., 2019). miR-200a-3p targeted MKK4 by binding to two independent sites on the 3'-untranslated region of dual-specificity MKK4 (Map2k4)/MKK4 mRNA. Shakespear et al. (2020) reported that treatment with a miR200a-3p mimetic attenuated cell death in $\mathrm{MPP}^{+}$-treated SH-SY5Y cells by suppressing both MKK4 mRNA and protein expression. 


\section{INVOLVEMENT OF MIRNAS IN ASTROCYTE DYSFUNCTION IN ALS}

One pathological feature of ALS in the brain is an increase in reactive astrocytes, which is associated with a low clearance efficiency of toxic excitatory glutamate neurotransmitters and impairments in neurotrophic factor secretion (Lasiene and Yamanaka, 2011). miR-218 is a motor neuron-specific miRNA that is involved in astrocyte function and the pathophysiology of ALS. miR-218 was shown to be released by dying motor neurons and taken up by astrocytes. Furthermore, miR-218 was shown to regulate the expression of the glutamate reuptake transporter excitatory amino acid transporter 2 (EAAT2) and be important for the proper regulation of excitatory glutamatergic neurotransmission (Ferraiuolo and Shaw, 2018; Ridler, 2018). Hoye et al. (2018) found that the downregulation of miR-218 ameliorated astrocyte dysfunction in ALS.

The expression of miR-124 is higher in human brain tissue, accounting for $25-48 \%$ of total miRNA in the adult brain, with the highest content in the cerebral cortex (Mishima et al., 2007). miR-124 can be combined with Jagged2 (Jag2, a ligand of Notch1) to significantly downregulate Jag2 expression, thereby inhibiting the Notch1 signaling pathway and promoting the transformation of cortical radial glial cells to astrocytes (Zhang et al., 2015). Approximately $20 \%$ of familial ALS cases are caused by SOD1 mutations (Rosen et al., 1993). Zhou et al. (2018) found that miR-124-positive cells were located mainly at sites of neurodegeneration in the spinal cord and brain stem in a transgenic mouse model of ALS. The levels of miR-124 increased in young (95-day-old) G93A-SOD1 mutant mice but decreased in older (108- and 122-day-old) mice compared with wild-type mice. These authors concluded that miR-124 is related to the differentiation of neural stem cells into astrocytes by targeting Sox2 and Sox9 (Zhou et al., 2018).

miR-146a is widely expressed in the immune system and is involved in the differentiation, proliferation, and activation of various immune cells. miR-146a was upregulated in IL-1 $\beta$ stimulated human astrocytes, indicating that the effects of this miRNA are associated with the regulation of an astrocytemediated inflammatory response (Iyer et al., 2012). miR-146a downregulation was reported to upregulate both interleukin-1 receptor-associated kinase 1 (IRAK1) and TNF receptorassociated factor 6 (TRAF6) in murine SOD1 astrocytes by impacting the TLR/NF- $\mathrm{kB}$ signaling pathways, thus contributing to neuroinflammation (Gomes et al., 2019).

\section{DEVELOPING MIRNA-BASED ASTROCYTE-REGULATORY THERAPEUTICS TO TREAT NEURODEGENERATIVE DISEASES}

The possibility of miRNA-based strategies to treat NDDs is an exciting approach. miRNA inhibition could pair mature miRNAs and prevent binding to target genes through chemically modified oligonucleotide sequences. miRNA removes target miRNAs from cultured cells through a "sponge" or "eraser" action (Ebert et al.,
2007; Van Rooij et al., 2008). miRNA mimetics or overexpression vectors have been used to rescue the suppression of endogenous miRNA expression levels in cells. With improvements in miRNA delivery, viral and non-viral vectors have been developed. Effective virus-based vectors have been developed for the stable and sustained expression of miRNAs. An intracranial injection of adeno-associated virus (AAV)-expressing miR-124-3p in APP/PS1-AD mice significantly reduced $A \beta$ deposition and improved cognitive function in AD mice (Zhou et al., 2019), suggesting high efficiency of the virus delivery system that can deliver miRNAs to the effective target cells. Liposomes, polymerbased systems, and inorganic nanoparticles are non-viral vector delivery systems that have also been widely used in clinical research (Labatut and Mattheolabakis, 2018). The use of tissuespecific promoters may allow miRNA-mimicking vectors to have greater specificity (To et al., 2020). miRNA-124-loaded polymeric nanoparticles that were injected in the ventricles in a mouse model of PD enhanced the migration of new neurons to the lesioned striatum, culminating in improvements in motor function (Saraiva et al., 2016). Although there is no conclusive evidence that miRNA therapeutics are effective in clinical trials for NDDs, further progress in delivering miRNA therapeutics to desired sites of action may contribute to clinical development. This transgenic approach has become a promising tool for detecting the function of miRNAs in different cell types and has the potential to become a future treatment (Karthikeyan et al., 2016).

Considering the large number of studies that suggest that astrocytes are involved in the pathogenesis of NDDs through various mechanisms, various studies have investigated therapeutic strategies for NDDs by regulating astrocyte function through miRNAs. Recent evidence suggests that peroxisome proliferator-activated receptors (PPARs) are actively involved in the modulation of astrocyte metabolism in NDDs (Martin et al., 2013; Joardar et al., 2015). The activation of PPAR $\beta / \delta$ suppressed the $\mathrm{CpG}$ island hypermethylation-associated silencing of miR-181a and protected against endoplasmic reticulum stress-induced damage to astrocytes, revealing a promising target for regulating endoplasmic reticulum stress-induced astrocyte injury (Pilakka-Kanthikeel et al., 2015). Ghasemi-Kasman et al. (2018b) used miR-302/367 and sodium valproate to demonstrate the possibility of astrocytes transforming into oligodendrocyte progenitor and myelin cells in a cuprizone-induced demyelination model. It was suggested that the specific targeting of astrocytes in vivo for forced expression of miR-302/367 cluster could increase the ability to repair myelin insults in cerebral structures through the generation of oligodendroglia by astrocytes, which opened a possible new avenue to enhance cerebral repair in NDDs (Ghasemi-Kasman et al., 2018b). The in vivo reprogramming of reactive astrocytes into functional neurons also suggested a new treatment strategy for AD. Ghasemi-Kasman et al. further found that the expression of a miR-302/367 cluster by the application of lentiviral particles enhanced the ability of the hippocampus and other brain structures to regenerate following neuronal loss in mice (Ghasemi-Kasman et al., 2017). These researchers also investigated the possible 
contribution of miR-302/367-induced induced neuronal activation to behavioral improvement and neural repair in an animal model of AD. Lentiviral particles assembled miR-302/367 ${ }^{+}$green fluorescent protein were injected in the dentate gyrus of the hippocampus, and short-term memory and spatial memory improved. Thus, the in vivo reprogramming of reactive astrocytes to neurons by the miR-302/367 cluster could be a feasible strategy to rescue learning and memory in $\mathrm{AD}$ patients (Ghasemi-Kasman et al., 2018a). Astrocyte toxicity contributes to motor neuron degeneration in ALS. Varcianna et al. performed a study to verify the link between miR-494-3p dysregulation and astrocyte-mediated motor neuron death. They found that miR-494-3p downregulated semaphorin 3A (Sema3A) levels in motor neurons and increased motor neuron survival in vitro, suggesting that miR-494-3p may be a therapeutic target for ALS (Varcianna et al., 2019).

Exosomes are $40-100 \mathrm{~nm}$ in diameter. They are a type of lipidic bilayer membrane-encapsulated vesicles that are released from cells to the extracellular space. Exosomes and the miRNAs, mRNAs, and proteins that they contain can reflect the pathophysiological state of source cells and are an important means of intercellular communication and the transport of biologically active substances, such as during the immune response, protein metabolism, and cell damage. The relationship between exosomal miRNAs and the pathogenesis of NDDs has prompted researchers to study their therapeutic potential. Based on in vivo striatal injections, exosome-mediated miRNAs (specifically miR-124a) were shown to play a role in neuron-toastrocyte signaling. Exosomes that were isolated in a conditioned medium that contained miRNA were internalized into astrocytes and increased miR-124a levels in astrocytes and GLT1 proteins in ALS. In a mouse model of end-stage ALS, miR-124a was selectively reduced in the spinal cord. Therefore, the in vivo exogenous transmission of $\mathrm{miR}-124 \mathrm{a}$ by a stereogenic injection

\section{REFERENCES}

Acosta, C., Anderson, H. D., and Anderson, C. M. (2017). Astrocyte dysfunction in Alzheimer disease. J. Neurosci. Res. 95, 2430-2447. doi: 10.1002/jnr.24075

Allaman, I., Bélanger, M., and Magistretti, P. J. (2011). Astrocyte-neuron metabolic relationships: for better and for worse. Trends Neurosci. 34, 76-87. doi: 10.1016/j.tins.2010.12.001

Almeida, M. I., Reis, R. M., and Calin, G. A. (2011). MicroRNA history: discovery, recent applications and next frontiers. Mutat. Res. 717, 1-8. doi: 10.1016/j. mrfmmm.2011.03.009

Anderson, M. A., Burda, J. E., Ren, Y., Ao, Y., O’shea, T. M., Kawaguchi, R., et al. (2016). Astrocyte scar formation aids central nervous system axon regeneration. Nature 532, 195-200. doi: 10.1038/nature17623

Bachoo, R. M., Kim, R. S., Ligon, K. L., Maher, E. A., Brennan, C., Billings, N., et al. (2004). Molecular diversity of astrocytes with implications for neurological disorders. Proc. Natl. Acad. Sci. U S A 101, 8384-8389. doi: 10.1073/pnas. 0402140101

Barbeito, L. H., Pehar, M., Cassina, P., Vargas, M. R., Peluffo, H., Viera, L., et al. (2004). A role for astrocytes in motor neuron loss in amyotrophic lateral sclerosis. Brain Res. Rev. 47, 263-274. doi: 10.1016/j.brainresrev.2004. 05.003

Birch, A. M., Katsouri, L., and Sastre, M. (2014). Modulation of inflammation in transgenic models of Alzheimer's disease. J. Neuroinflammation 11, 25-25. doi: 10.1186/1742-2094-11-25 prevented the further pathological loss of GLT1 protein in cultured astrocytes in the ALS mouse model (Morel et al., 2013; Izadpanah et al., 2018). Exosomes that were loaded with miRNAs have broad prospects for the treatment of NDDs. However, the application of exosome manipulation techniques for the effective treatment of NDDs needs to be optimized and standardized.

Research on the application of miRNA expression technology to regulate astrocyte function for the treatment of NDDs is limited. Nonetheless, strong evidence of the role of astrocytes in the pathogenesis and progression of NDDs and advances in miRNA treatment technology may provide a theoretical basis for the early application of this therapeutic strategy in NDDs.

\section{CONCLUSIONS}

We reviewed current knowledge of the role of astrocytes in NDDs. Several studies have focused on interactions between miRNAs and astrocyte functions to elucidate the molecular mechanisms of NDDs. The regulation of astrocyte functions in various mechanisms that contribute to NDDs may lead to new therapeutic strategies. However, the cell-specific delivery of miRNAs in the brain in vivo remains challenging. Manipulations of miRNAs can also have unpredictable effects on mRNA expression. Several challenges remain in the development of new therapeutic strategies that target miRNAs to regulate astrocyte function. Further research in this area will help fill gaps in our understanding of the role of miRNAs in NDDs and may have important clinical implications.

\section{AUTHOR CONTRIBUTIONS}

This manuscript was primarily written by YB, XS, and ZJ. The figure was produced by LP and RJ. RJ contributed to editing the manuscript. All authors contributed to the article and approved the submitted version.

Blasko, I., Veerhuis, R., Stampfer-Kountchev, M., Saurwein-Teissl, M. Eikelenboom, P., and Grubeck-Loebenstein, B. (2000). Costimulatory effects of interferon-gamma and interleukin-1 $\beta$ or tumor necrosis factor alpha on the synthesis of A $\beta 1-40$ and A $\beta 1-42$ by human astrocytes. Neurobiol. Dis. 7, 682-689. doi: 10.1016/j.jchemneu.2020.101852

Bradford, J., Shin, J.-Y., Roberts, M., Wang, C.-E., Li, X.-J., and Li, S. (2009). Expression of mutant huntingtin in mouse brain astrocytes causes age-dependent neurological symptoms. Proc. Natl. Acad. Sci. U S A 106, 22480-22485. doi: 10.1073/pnas.0911503106

Brambilla, R. (2019). The contribution of astrocytes to the neuroinflammatory response in multiple sclerosis and experimental autoimmune encephalomyelitis. Acta Neuropathol. 137, 757-783. doi: 10.1007/s00401019-01980-7

Bruen, R., Fitzsimons, S., and Belton, O. (2019). miR-155 in the resolution of atherosclerosis. Front. Pharmacol. 10:463. doi: 10.3389/fphar.2019.00463

Bussian, T. J., Aziz, A., Meyer, C. F., Swenson, B. L., Van Deursen, J. M., and Baker, D. J. (2018). Clearance of senescent glial cells prevents tau-dependent pathology and cognitive decline. Nature 562, 578-582. doi: 10.1038/s41586018-0543-y

Cacace, F., Mineo, D., Viscomi, M. T., Latagliata, E. C., Mancini, M., Sasso, V., et al. (2017). Intermittent theta-burst stimulation rescues dopamine-dependent corticostriatal synaptic plasticity and motor behavior in experimental parkinsonism: possible role of glial activity. Mov. Disord. 32, 1035-1046. doi: $10.1002 / \mathrm{mds} .26982$ 
Choi, C., Park, J. Y., Lee, J., Lim, J. H., Shin, E. C., Ahn, Y. S., et al. (1999). Fas ligand and Fas are expressed constitutively in human astrocytes and the expression increases with IL-1, IL-6, TNF- $\alpha$, or IFN- $\gamma$. J. Immunol. 162, 1889-1895.

Choi, I., Woo, J. H., Jou, I., and Joe, E.-H. (2016). PINK1 deficiency decreases expression levels of mir-326, mir-330 and mir-3099 during brain development and neural stem cell differentiation. Exp. Neurobiol. 25, 14-23. doi: 10.5607/en. 2016.25.1.14

Cressatti, M., Song, W., Turk, A. Z., Garabed, L. R., Benchaya, J. A., Galindez, C., et al. (2019). Glial HMOX1 expression promotes central and peripheral $\alpha$-synuclein dysregulation and pathogenicity in parkinsonian mice. Glia 67, 1730-1744. doi: 10.1002/glia.23645

Cui, J. G., Li, Y. Y., Zhao, Y., Bhattacharjee, S., and Lukiw, W. J. (2010). Differential regulation of interleukin-1 receptor-associated kinase-1 (IRAK-1) and IRAK-2 by microRNA-146a and NF- $\mathrm{KB}$ in stressed human astroglial cells and in Alzheimer disease. J. Biol. Chem. 285, 38951-38960. doi: 10.1074/jbc.M110. 178848

Desvignes, T., Batzel, P., Berezikov, E., Eilbeck, K., Eppig, J. T., Mcandrews, M. S., et al. (2015). miRNA nomenclature: a view incorporating genetic origins, biosynthetic pathways and sequence variants. Trends Genet. 31, 613-626. doi: 10.1016/j.tig.2015.09.002

Di Domenico, A., Carola, G., Calatayud, C., Pons-Espinal, M., Muñoz, J. P., Richaud-Patin, Y., et al. (2019). Patient-specific iPSC-derived astrocytes contribute to non-cell-autonomous neurodegeneration in Parkinson's disease. Stem Cell Reports 12, 213-229. doi: 10.1016/j.stemcr.2018. 12.011

Ebert, M. S., Neilson, J. R., and Sharp, P. A. (2007). MicroRNA sponges: competitive inhibitors of small RNAs in mammalian cells. Nat. Methods 4, 721-726. doi: 10.1038/nmeth1079

Ferraiuolo, L., and Shaw, P. J. (2018). Lost in translation: microRNAs mediate pathological cross-talk between motor neurons and astrocytes. Brain 141, 2534-2536. doi: 10.1093/brain/awy213

Ghasemi-Kasman, M., Baharvand, H., and Javan, M. (2017). Enhanced neurogenesis in degenerated hippocampi following pretreatment with miR302/367 expressing lentiviral vector in mice. Biomed. Pharmacother. 96, 1222-1229. doi: 10.1016/j.biopha.2017.11.094

Ghasemi-Kasman, M., Shojaei, A., Gol, M., Moghadamnia, A. A., Baharvand, H., and Javan, M. (2018a). miR-302/367-induced neurons reduce behavioral impairment in an experimental model of Alzheimer's disease. Mol. Cell. Neurosci. 86, 50-57. doi: 10.1016/j.mcn.2017.11.012

Ghasemi-Kasman, M., Zare, L., Baharvand, H., and Javan, M. (2018b). In vivo conversion of astrocytes to myelinating cells by miR-302/367 and valproate to enhance myelin repair. J. Tissue Eng. Regen. Med. 12, e462-e472. doi: 10.1002/term.2276

Giovagnoli, A. R., Manfredi, V., Schifano, L., Paterlini, C., Parente, A., and Tagliavini, F. (2018). Combining drug and music therapy in patients with moderate Alzheimer's disease: a randomized study. Neurol. Sci. 39, 1021-1028. doi: 10.1007/s10072-018-3316-3

Gomes, C., Cunha, C., Nascimento, F., Ribeiro, J. A., Vaz, A. R., and Brites, D. (2019). Cortical neurotoxic astrocytes with early ALS pathology and miR-146a deficit replicate gliosis markers of symptomatic SOD1G93A mouse model. Mol. Neurobiol. 56, 2137-2158. doi: 10.1007/s12035-0181220-8

Gómez-Gonzalo, M., Martin-Fernandez, M., Martínez-Murillo, R., Mederos, S., Hernández-Vivanco, A., Jamison, S., et al. (2017). Neuron-astrocyte signaling is preserved in the aging brain. Glia 65, 569-580. doi: 10.1002/glia. 23112

Gong, Y. H., Parsadanian, A. S., Andreeva, A., Snider, W. D., and Elliott, J. L. (2000). Restricted expression of $\mathrm{G} 86 \mathrm{R} \mathrm{Cu} / \mathrm{Zn}$ superoxide dismutase in astrocytes results in astrocytosis but does not cause motoneuron degeneration. J. Neurosci. 20, 660-665. doi: 10.1523/JNEUROSCI.20-02-00660.2000

Goodall, E. F., Heath, P. R., Bandmann, O., Kirby, J., and Shaw, P. J. (2013). Neuronal dark matter: the emerging role of microRNAs in neurodegeneration. Front. Cell. Neurosci. 7:178. doi: 10.3389/fncel.2013.00178

Guedes, J. R., Custódia, C. M., Silva, R. J., De Almeida, L. P., Pedroso De Lima, M. C., and Cardoso, A. L. (2014). Early miR-155 upregulation contributes to neuroinflammation in Alzheimer's disease triple transgenic mouse model. Hum. Mol. Genet. 23, 6286-6301. doi: 10.1093/hmg/ddu348
Han, D., Dong, X., Zheng, D., and Nao, J. (2019). MiR-124 and the underlying therapeutic promise of neurodegenerative disorders. Front. Pharmacol. 10:1555. doi: 10.3389/fphar.2019.01555

Heath, P. R., and Shaw, P. J. (2002). Update on the glutamatergic neurotransmitter system and the role of excitotoxicity in amyotrophic lateral sclerosis. Muscle Nerve 26, 438-458. doi: 10.1002/mus. 10186

Heemels, M.-T. (2016). Neurodegenerative diseases. Nature 539, 179-179. doi: $10.1038 / 539179$ a

Hoye, M. L., Regan, M. R., Jensen, L. A., Lake, A. M., Reddy, L. V., Vidensky, S., et al. (2018). Motor neuron-derived microRNAs cause astrocyte dysfunction in amyotrophic lateral sclerosis. Brain 141, 2561-2575. doi: 10.1093/brain/awy182

Hsiao, H. Y., Chen, Y. C., Chen, H. M., Tu, P. H., and Chern, Y. (2013). A critical role of astrocyte-mediated nuclear factor-кB-dependent inflammation in Huntington's disease. Hum. Mol. Genet. 22, 1826-1842. doi: $10.1093 / \mathrm{hmg} / \mathrm{ddt} 036$

Hunot, S., Brugg, B., Ricard, D., Michel, P. P., Muriel, M. P., Ruberg, M., et al. (1997). Nuclear translocation of NF-кB is increased in dopaminergic neurons of patients with parkinson disease. Proc. Natl. Acad. Sci. U S A 94, 7531-7536. doi: $10.1073 /$ pnas.94.14.7531

Izecka, J. (2003). Prostaglandin E2 is increased in amyotrophic lateral sclerosis patients. Acta Neurol. Scand. 108, 125-129. doi: 10.1034/j.1600-0404.2003. 00102.x

Iyer, A., Zurolo, E., Prabowo, A., Fluiter, K., Spliet, W. G. M., Van Rijen, P. C., et al. (2012). MicroRNA-146a: a key regulator of astrocyte-mediated inflammatory response. PLoS One 7:e44789. doi: 10.1371/journal.pone. 0044789

Izadpanah, M., Seddigh, A., Ebrahimi Barough, S., Fazeli, S. A. S., and Ai, J. (2018). Potential of extracellular vesicles in neurodegenerative diseases: diagnostic and therapeutic indications. J. Mol. Neurosci. 66, 172-179. doi: 10.1007/s12031-0181135-x

Jiang, R., Diaz-Castro, B., Looger, L. L., and Khakh, B. S. (2016). Dysfunctional calcium and glutamate signaling in striatal astrocytes from Huntington's disease model mice. J. Neurosci. 36, 3453-3470. doi: 10.1523/JNEUROSCI. 3693-15.2016

Joardar, A., Menzl, J., Podolsky, T. C., Manzo, E., Estes, P. S., Ashford, S., et al. (2015). PPAR gamma activation is neuroprotective in a Drosophila model of ALS based on TDP-43. Hum. Mol. Genet. 24, 1741-1754. doi: 10.1093/hmg/ddu587

Jordan, K., Murphy, J., Singh, A., and Mitchell, C. S. (2018). Astrocyte-mediated neuromodulatory regulation in preclinical ALS: a metadata analysis. Front. Cell. Neurosci. 12, 491-491. doi: 10.3389/fncel.2018.00491

Kalmar, B., Lu, C.-H., and Greensmith, L. (2014). The role of heat shock proteins in amyotrophic lateral sclerosis: the therapeutic potential of arimoclomol. Pharmacol. Ther. 141, 40-54. doi: 10.1016/j.pharmthera.2013.08.003

Karthikeyan, A., Patnala, R., Jadhav, S. P., Eng-Ang, L., and Dheen, S. T. (2016). MicroRNAs: key players in microglia and astrocyte mediated inflammation in CNS pathologies. Curr. Med. Chem. 23, 3528-3546. doi: 10.2174/0929867323666160814001040

Kaur, D., Sharma, V., and Deshmukh, R. (2019). Activation of microglia and astrocytes: a roadway to neuroinflammation and Alzheimer's disease. Inflammopharmacology 27, 663-677. doi: 10.1007/s10787-019-00580-x

Kawamata, H., and Manfredi, G. (2010). Mitochondrial dysfunction and intracellular calcium dysregulation in ALS. Mech. Ageing Dev. 131, 517-526. doi: 10.1016/j.mad.2010.05.003

Khakh, B. S., and Sofroniew, M. V. (2015). Diversity of astrocyte functions and phenotypes in neural circuits. Nat. Neurosci. 18, 942-952. doi: 10.1038/nn.4043 Kiernan, M. C., Vucic, S., Cheah, B. C., Turner, M. R., Eisen, A., Hardiman, O., et al. (2011). Amyotrophic lateral sclerosis. Lancet 377, 942-955. doi: 10.1016/S0140-6736(10)61156-7

Ko, H. M., Lee, S. H., Bang, M., Kim, K. C., Jeon, S. J., Park, Y.-M., et al. (2018). Tyrosine kinase Fyn regulates iNOS expression in LPS-stimulated astrocytes via modulation of ERK phosphorylation. Biochem. Biophys. Res. Commun. 495, 1214-1220. doi: 10.1016/j.bbrc.2017.11.143

Kosuge, Y., Miyagishi, H., Yoneoka, Y., Yoneda, K., Nango, H., Ishige, K., et al. (2018). Pathophysiological role of prostaglandin E2-induced up-regulation of the EP2 receptor in motor neuron-like NSC-34 cells and lumbar motor neurons in ALS model mice. Neurochem. Int. 119, 132-139. doi: 10.1016/j.neuint.2017. 06.013 
Krishnan, J., Vannuvel, K., Andries, M., Waelkens, E., Robberecht, W., and Van Den Bosch, L. (2008). Over-expression of Hsp27 does not influence disease in the mutant SOD1(G93A) mouse model of amyotrophic lateral sclerosis. J. Neurochem. 106, 2170-2183. doi: 10.1111/j.1471-4159.2008.05545.x

Kuter, K., Olech, Ł., and Głowacka, U. (2018). Prolonged dysfunction of astrocytes and activation of microglia accelerate degeneration of dopaminergic neurons in the rat substantia nigra and block compensation of early motor dysfunction induced by 6-OHDA. Mol. Neurobiol. 55, 3049-3066. doi: 10.1007/s12035-0170529-z

Labatut, A. E., and Mattheolabakis, G. (2018). Non-viral based miR delivery and recent developments. Eur. J. Pharm. Biopharm. 128, 82-90. doi: 10.1016/j.ejpb. 2018.04.018

Lasiene, J., and Yamanaka, K. (2011). Glial cells in amyotrophic lateral sclerosis. Neurol. Res. Int. 2011, 718987-718987. doi: 10.1155/2011/718987

Lau, A., So, R. W. L., Lau, H. H. C., Sang, J. C., Ruiz-Riquelme, A., Fleck, S. C., et al. (2020). $\alpha$-Synuclein strains target distinct brain regions and cell types. Nat. Neurosci. 23, 21-31. doi: 10.1038/s41593-019-0541-x

Lee, W.-S., Shin, J.-S., Jang, D. S., and Lee, K.-T. (2016). Cnidilide, an alkylphthalide isolated from the roots of Cnidium officinale, suppresses LPS-induced NO, PGE(2), IL- $1 \beta$, IL- 6 and TNF- $\alpha$ production by AP- 1 and NF- $\mathrm{KB}$ inactivation in RAW 264.7 macrophages. Int. Immunopharmacol. 40, 146-155. doi: 10.1016/j.intimp.2016.08.021

Leidinger, P., Backes, C., Deutscher, S., Schmitt, K., Mueller, S. C., Frese, K., et al. (2013). A blood based 12-miRNA signature of Alzheimer disease patients. Genome Biol. 14:R78. doi: 10.1186/gb-2013-14-7-r78

Liddelow, S. A., and Barres, B. A. (2017). Reactive astrocytes: production, function and therapeutic potential. Immunity 46, 957-967. doi: 10.1016/j.immuni.2017. 06.006

Liddelow, S. A., Guttenplan, K. A., Clarke, L. E., Bennett, F. C., Bohlen, C. J., Schirmer, L., et al. (2017). Neurotoxic reactive astrocytes are induced by activated microglia. Nature 541, 481-487. doi: 10.1038/nature21029

Lind, B. L., Jessen, S. B., Lønstrup, M., Joséphine, C., Bonvento, G., and Lauritzen, M. (2018). Fast $\mathrm{Ca}^{2+}$ responses in astrocyte end-feet and neurovascular coupling in mice. Glia 66, 348-358. doi: 10.1002/glia.23246

Lyon, M. S., Wosiski-Kuhn, M., Gillespie, R., Caress, J., and Milligan, C. (2019). Inflammation, immunity and amyotrophic lateral sclerosis: I. etiology and pathology. Muscle Nerve 59, 10-22. doi: 10.1002/mus.26289

Martin, H. L., Mounsey, R. B., Sathe, K., Mustafa, S., Nelson, M. C., Evans, R. M., et al. (2013). A peroxisome proliferator-activated receptor- $\delta$ agonist provides neuroprotection in the 1-methyl-4-phenyl-1,2,3,6-tetrahydropyridine model of Parkinson's disease. Neuroscience 240, 191-203. doi: 10.1016/j.neuroscience. 2013.02.058

Marttinen, M., Takalo, M., Natunen, T., Wittrahm, R., Gabbouj, S., Kemppainen, S., et al. (2018). Molecular mechanisms of synaptotoxicity and neuroinflammation in Alzheimer's disease. Front. Neurosci. 12, 963-963. doi: $10.3389 /$ fnins. 2018.00963

Meares, G. P., Rajbhandari, R., Gerigk, M., Tien, C.-L., Chang, C., Fehling, S. C., et al. (2018). MicroRNA-31 is required for astrocyte specification. Glia 66, 987-998. doi: 10.1002/glia.23296

Meraz-Ríos, M. A., Toral-Rios, D., Franco-Bocanegra, D., Villeda-Hernández, J., and Campos-Peña, V. (2013). Inflammatory process in Alzheimer's disease. Front. Integr. Neurosci. 7, 59-59. doi: 10.1097/JCN.0000000000000616

Mishima, T., Mizuguchi, Y., Kawahigashi, Y., Takizawa, T., and Takizawa, T. (2007). RT-PCR-based analysis of microRNA (miR-1 and -124) expression in mouse CNS. Brain Res. 1131, 37-43. doi: 10.1016/j.brainres.2006.11.035

Miyagishi, H., Kosuge, Y., Takano, A., Endo, M., Nango, H., YamagataMurayama, S., et al. (2017). Increased expression of 15-hydroxyprostaglandin dehydrogenase in spinal astrocytes during disease progression in a model of amyotrophic lateral sclerosis. Cell. Mol. Neurobiol. 37, 445-452. doi: 10.1007/s10571-016-0377-9

Morale, M. C., Serra, P. A., L'episcopo, F., Tirolo, C., Caniglia, S., Testa, N., et al. (2006). Estrogen, neuroinflammation and neuroprotection in Parkinson's disease: glia dictates resistance versus vulnerability to neurodegeneration. Neuroscience 138, 869-878. doi: 10.1016/j.neuroscience.2005.07.060

Morel, L., Regan, M., Higashimori, H., Ng, S. K., Esau, C., Vidensky, S., et al. (2013). Neuronal exosomal miRNA-dependent translational regulation of astroglial glutamate transporter GLT1. J. Biol. Chem. 288, 7105-7116. doi: 10.1074/jbc.M112.410944
Mulder, S. D., Veerhuis, R., Blankenstein, M. A., and Nielsen, H. M. (2012). The effect of amyloid associated proteins on the expression of genes involved in amyloid- $\beta$ clearance by adult human astrocytes. Exp. Neurol. 233, 373-379. doi: 10.1016/j.expneurol.2011.11.001

Muramatsu, Y., Kurosaki, R., Watanabe, H., Michimata, M., Matsubara, M., Imai, Y., et al. (2003). Expression of S-100 protein is related to neuronal damage in MPTP-treated mice. Glia 42, 307-313. doi: 10.1002/glia. 10225

Neal, M. L., Boyle, A. M., Budge, K. M., Safadi, F. F., and Richardson, J. R. (2018). The glycoprotein GPNMB attenuates astrocyte inflammatory responses through the CD44 receptor. J. Neuroinflammation 15:73. doi: 10.1186/s12974018-1100-1

Neal, M., and Richardson, J. R. (2018). Epigenetic regulation of astrocyte function in neuroinflammation and neurodegeneration. Biochim. Biophys. Acta Mol. Basis Dis. 1864, 432-443. doi: 10.1016/j.bbadis.2017.11.004

Neo, W. H., Yap, K., Lee, S. H., Looi, L. S., Khandelia, P., Neo, S. X., et al. (2014). MicroRNA miR-124 controls the choice between neuronal and astrocyte differentiation by fine-tuning Ezh2 expression. J. Biol. Chem. 289, 20788-20801. doi: 10.1074/jbc.M113.525493

Ogura, M., Kikuchi, H., Shakespear, N., Suzuki, T., Yamaki, J., Homma, M. K., et al. (2019). Prenylated quinolinecarboxylic acid derivative prevents neuronal cell death through inhibition of MKK4. Biochem. Pharmacol. 162, 109-122. doi: 10.1016/j.bcp.2018.10.008

Owens, B. (2017). Amyotrophic lateral sclerosis. Nature 550, S105-S105. doi: $10.1038 / 550 S 105 a$

Pilakka-Kanthikeel, S., Raymond, A., Atluri, V. S. R., Sagar, V., Saxena, S. K., Diaz, P., et al. (2015). Sterile alpha motif and histidine/aspartic acid domain-containing protein 1 (SAMHD1)-facilitated HIV restriction in astrocytes is regulated by miRNA-181a. J. Neuroinflammation 12, 66-66. doi: 10.1186/s12974-015-0285-9

Qin, L., Wu, X., Block, M. L., Liu, Y., Breese, G. R., Hong, J.-S., et al. (2007). Systemic LPS causes chronic neuroinflammation and progressive neurodegeneration. Glia 55, 453-462. doi: 10.1002/glia.20467

Ridet, J. L., Malhotra, S. K., Privat, A., and Gage, F. H. (1997). Reactive astrocytes: cellular and molecular cues to biological function. Trends Neurosci. 20, 570-577. doi: 10.1016/s0166-2236(97)01139-9

Ridler, C. (2018). MicroRNA from dying neurons triggers astrocytosis in ALS. Nat. Rev. Neurol. 14, 572-572. doi: 10.1038/s41582-018-0052-5

Rivetti Di Val Cervo, P., Romanov, R. A., Spigolon, G., Masini, D., MartínMontañez, E., Toledo, E. M., et al. (2017). Induction of functional dopamine neurons from human astrocytes in vitro and mouse astrocytes in a Parkinson's disease model. Nat. Biotechnol. 35, 444-452. doi: 10.1038/ nbt. 3835

Rolyan, H., Feike, A. C., Upadhaya, A. R., Waha, A., Van Dooren, T., Haass, C., et al. (2011). Amyloid- $\beta$ protein modulates the perivascular clearance of neuronal apolipoprotein E in mouse models of Alzheimer's disease. J. Neural Transm. 118, 699-712. doi: 10.1007/s00702-010-0572-7

Rosen, D. R., Siddique, T., Patterson, D., Figlewicz, D. A., Sapp, P., Hentati, A., et al. (1993). Mutations in $\mathrm{Cu} / \mathrm{Zn}$ superoxide dismutase gene are associated with familial amyotrophic lateral sclerosis. Nature 362, 59-62. doi: $10.1038 / 362059 \mathrm{a} 0$

Rossner, S., Lange-Dohna, C., Zeitschel, U., and Perez-Polo, J. R. (2005). Alzheimer's disease beta-secretase BACE1 is not a neuron-specific enzyme. J. Neurochem. 92, 226-234. doi: 10.1111/j.1471-4159.2004.02857.x

Rothstein, J. D., Van Kammen, M., Levey, A. I., Martin, L. J., and Kuncl, R. W. (1995). Selective loss of glial glutamate transporter GLT-1 in amyotrophic lateral sclerosis. Ann. Neurol. 38, 73-84. doi: 10.1002/ana.410380114

Ruppert, M. C., Greuel, A., Tahmasian, M., Schwartz, F., Stürmer, S., Maier, F., et al. (2020). Network degeneration in Parkinson's disease: multimodal imaging of nigro-striato-cortical dysfunction. Brain 143, 944-959. doi: 10.1093/brain/awaa019

Saghazadeh, A., Ferrari, C. C., and Rezaei, N. (2016). Deciphering variability in the role of interleukin-1 $\beta$ in Parkinson's disease. Rev. Neurosci. 27, 635-650. doi: 10.1515/revneuro-2015-0059

Saporito, M. S., Thomas, B. A., and Scott, R. W. (2000). MPTP activates c-Jun $\mathrm{NH}(2)$-terminal kinase (JNK) and its upstream regulatory kinase MKK4 in nigrostriatal neurons in vivo. J. Neurochem. 75, 1200-1208. doi: 10.1046/j.14714159.2000.0751200.x 
Saraiva, C., Ferreira, L., and Bernardino, L. (2016). Traceable microRNA-124 loaded nanoparticles as a new promising therapeutic tool for Parkinson's disease. Neurogenesis (Austin) 3:e1256855. doi: 10.1080/23262133.2016. 1256855

Schuitemaker, A., Dik, M. G., Veerhuis, R., Scheltens, P., Schoonenboom, N. S. M., Hack, C. E., et al. (2009). Inflammatory markers in AD and MCI patients with different biomarker profiles. Neurobiol. Aging 30, 1885-1889. doi: 10.1016/j. neurobiolaging.2008.01.014

Seyedhassantehrani, N., Li, Y., and Yao, L. (2016). Dynamic behaviors of astrocytes in chemically modified fibrin and collagen hydrogels. Integr. Biol. 8, 624-634. doi: 10.1039/c6ib00003g

Shakespear, N., Ogura, M., Yamaki, J., and Homma, Y. (2020). Astrocyte-derived exosomal microRNA miR-200a-3p prevents $\mathrm{MPP}^{+}$-induced apoptotic cell death through down-regulation of MKK4. Neurochem. Res. 45, 1020-1033. doi: 10.1007/s11064-020-02977-5

Shin, J.-Y., Fang, Z.-H., Yu, Z.-X., Wang, C.-E., Li, S.-H., and Li, X.-J. (2005). Expression of mutant huntingtin in glial cells contributes to neuronal excitotoxicity. J. Cell Biol. 171, 1001-1012. doi: 10.1083/jcb.200508072

Sofroniew, M. V. (2014). Multiple roles for astrocytes as effectors of cytokines and inflammatory mediators. Neuroscientist 20, 160-172. doi: $10.1177 / 1073858413504466$

Sofroniew, M. V., and Vinters, H. V. (2010). Astrocytes: biology and pathology. Acta Neuropathol. 119, 7-35. doi: 10.1007/s00401-009-0619-8

Starczynowski, D. T., Kuchenbauer, F., Wegrzyn, J., Rouhi, A., Petriv, O., Hansen, C. L., et al. (2011). MicroRNA-146a disrupts hematopoietic differentiation and survival. Exp. Hematol. 39, 167.e4-178.e4. doi: 10.1016/j. exphem.2010.09.011

Stenvang, J., and Kauppinen, S. (2008). MicroRNAs as targets for antisense-based therapeutics. Expert Opin. Biol. Ther. 8, 59-81. doi: 10.1517/14712598.8.1.59

Taganov, K. D., Boldin, M. P., Chang, K. J., and Baltimore, D. (2006). NF-кBdependent induction of microRNA miR-146, an inhibitor targeted to signaling proteins of innate immune responses. Proc. Natl. Acad. Sci. U S A 103, 12481-12486. doi: 10.1073/pnas.0605298103

To, K. K. W., Fong, W., Tong, C. W. S., Wu, M., Yan, W., and Cho, W. C. S. (2020). Advances in the discovery of microRNA-based anticancer therapeutics: latest tools and developments. Expert Opin. Drug Discov. 15, 63-83. doi: $10.1080 / 17460441.2020 .1690449$

Tobore, T. O. (2019). On the central role of mitochondria dysfunction and oxidative stress in Alzheimer's disease. Neurol. Sci. 40, 1527-1540. doi: 10.1007/s10072-019-03863-x

Tong, X., Ao, Y., Faas, G. C., Nwaobi, S. E., Xu, J., Haustein, M. D., et al. (2014). Astrocyte Kir4.1 ion channel deficits contribute to neuronal dysfunction in Huntington's disease model mice. Nat. Neurosci. 17, 694-703. doi: 10.1038/ nn.3691

Tripathi, P., Rodriguez-Muela, N., Klim, J. R., De Boer, A. S., Agrawal, S., Sandoe, J., et al. (2017). Reactive astrocytes promote ALS-like degeneration and intracellular protein aggregation in human motor neurons by disrupting autophagy through TGF- $\beta 1$. Stem Cell Reports 9, 667-680. doi: 10.1016/j. stemcr.2017.06.008

Turnquist, C., Horikawa, I., Foran, E., Major, E. O., Vojtesek, B., Lane, D. P., et al. (2016). p53 isoforms regulate astrocyte-mediated neuroprotection and neurodegeneration. Cell Death Differ. 23, 1515-1528. doi: 10.1038/cdd. 2016.37

Van Damme, P., Bogaert, E., Dewil, M., Hersmus, N., Kiraly, D., Scheveneels, W., et al. (2007). Astrocytes regulate GluR2 expression in motor neurons and their vulnerability to excitotoxicity. Proc. Natl. Acad. Sci. U S A 104, 14825-14830. doi: 10.1073/pnas.0705046104

Van Rooij, E., Marshall, W. S., and Olson, E. N. (2008). Toward microRNA-based therapeutics for heart disease: the sense in antisense. Cir. Res. 103, 919-928. doi: 10.1161/CIRCRESAHA.108.183426

Van Scheppingen, J., Mills, J. D., Zimmer, T. S., Broekaart, D. W. M., Iori, V., Bongaarts, A., et al. (2018). miR147b: a novel key regulator of interleukin 1 beta-mediated inflammation in human astrocytes. Glia 66, 1082-1097. doi: $10.1002 /$ glia. 23302

Varcianna, A., Myszczynska, M. A., Castelli, L. M., O’neill, B., Kim, Y., Talbot, J., et al. (2019). Micro-RNAs secreted through astrocyte-derived extracellular vesicles cause neuronal network degeneration in C9orf72 ALS. EBioMedicine 40, 626-635. doi: 10.1016/j.ebiom.2018.11.067
Veeraraghavalu, K., Zhang, C., Zhang, X., Tanzi, R. E., and Sisodia, S. S. (2014). Age-dependent, non-cell-autonomous deposition of amyloid from synthesis of $\beta$-amyloid by cells other than excitatory neurons. J. Neurosci. 34, 3668-3673. doi: 10.1523/JNEUROSCI.5079-13.2014

Vermeiren, C., Hemptinne, I., Vanhoutte, N., Tilleux, S., Maloteaux, J.-M., and Hermans, E. (2006). Loss of metabotropic glutamate receptor-mediated regulation of glutamate transport in chemically activated astrocytes in a rat model of amyotrophic lateral sclerosis. J. Neurochem. 96, 719-731. doi: 10.1111/j.1471-4159.2005.03577.x

Yamanaka, K., and Komine, O. (2018). The multi-dimensional roles of astrocytes in ALS. Neurosci. Res. 126, 31-38. doi: 10.1016/j.neures.2017.09.011

Yang, S.-H. (2019). Cellular and molecular mediators of neuroinflammation in Alzheimer disease. Int. Neurourol. J. 23, S54-S62. doi: 10.5213/inj.1938184.092

Yang, N., Liang, Y., Yang, P., Wang, W., Zhang, X., and Wang, J. (2016). TNF- $\alpha$ receptor antagonist attenuates isoflurane-induced cognitive impairment in aged rats. Exp. Ther. Med. 12, 463-468. doi: 10.3892/etm.2016.3262

Yasojima, K., Tourtellotte, W. W., Mcgeer, E. G., and Mcgeer, P. L. (2001). Marked increase in cyclooxygenase-2 in ALS spinal cord: implications for therapy. Neurology 57, 952-956. doi: 10.1212/wnl.57.6.952

Zeng, Y., Yi, R., and Cullen, B. R. (2003). MicroRNAs and small interfering RNAs can inhibit mRNA expression by similar mechanisms. Proc. Natl. Acad. Sci. U S A 100, 9779-9784. doi: 10.1073/pnas.1630797100

Zhang, C., Ge, X., Liu, Q., Jiang, M., Li, M. W., and Li, H. (2015). MicroRNA-mediated non-cell-autonomous regulation of cortical radial glial transformation revealed by a Dicer1 knockout mouse model. Glia 63, 860-876. doi: 10.1002/glia.22789

Zhang, S., Liu, D., Ye, D., Li, H., and Chen, F. (2017). Can music-based movement therapy improve motor dysfunction in patients with Parkinson's disease? Systematic review and meta-analysis. Neurol. Sci. 38, 1629-1636. doi: 10.1007/s10072-017-3020-8

Zhang, X., Wan, J.-Q., and Tong, X.-P. (2018). Potassium channel dysfunction in neurons and astrocytes in Huntington's disease. CNS Neurosci. Ther. 24, 311-318. doi: 10.1111/cns.12804

Zhao, T., Hong, Y., Li, S., and Li, X.-J. (2016). Compartment-dependent degradation of mutant huntingtin accounts for its preferential accumulation in neuronal processes. J. Neurosci. 36, 8317-8328. doi: 10.1523/JNEUROSCI. 0806-16.2016

Zhou, Y., Deng, J., Chu, X., Zhao, Y., and Guo, Y. (2019). Role of post-transcriptional control of calpain by miR-124-3p in the development of Alzheimer's disease. J. Alzheimers Dis. 67, 571-581. doi: 10.3233/JAD-181053

Zhou, F., Zhang, C., Guan, Y., Chen, Y., Lu, Q., Jie, L., et al. (2018). Screening the expression characteristics of several miRNAs in G93A-SOD1 transgenic mouse: altered expression of miRNA-124 is associated with astrocyte differentiation by targeting Sox2 and Sox9. J. Neurochem. 145, 51-67. doi: 10.1111/jnc.14229

Zhu, Y., and Wang, J. (2015). Wogonin increases $\beta$-amyloid clearance and inhibits tau phosphorylation via inhibition of mammalian target of rapamycin: potential drug to treat Alzheimer's disease. Neurol. Sci. 36, 1181-1188. doi: 10.1007/s10072-015-2070-Z

Zumkehr, J., Rodriguez-Ortiz, C. J., Cheng, D., Kieu, Z., Wai, T., Hawkins, C., et al. (2015). Ceftriaxone ameliorates tau pathology and cognitive decline via restoration of glial glutamate transporter in a mouse model of Alzheimer's disease. Neurobiol. Aging 36, 2260-2271. doi: 10.1016/j.neurobiolaging.2015. 04.005

Zumkehr, J., Rodriguez-Ortiz, C. J., Medeiros, R., and Kitazawa, M. (2018). Inflammatory cytokine, IL- $1 \beta$, regulates glial glutamate transporter via microRNA-181a in vitro. J. Alzheimers Dis. 63, 965-975. doi: 10.3233/JAD170828

Conflict of Interest: The authors declare that the research was conducted in the absence of any commercial or financial relationships that could be construed as a potential conflict of interest.

Copyright $(2021$ Bai, Su, Piao, Jin and Jin. This is an open-access article distributed under the terms of the Creative Commons Attribution License (CC BY). The use, distribution or reproduction in other forums is permitted, provided the original author(s) and the copyright owner(s) are credited and that the original publication in this journal is cited, in accordance with accepted academic practice. No use, distribution or reproduction is permitted which does not comply with these terms. 